\title{
Examining the Technology Acceptance Model for E-Loan Application Services among University Students in Kenya
}

\author{
Teresah W. Wanjiku ${ }^{1}$, Joseph N. Mwangi ${ }^{2}$, Vincent N. Omollo ${ }^{3}$ \\ School of Computing and IT, Jomo Kenyatta University of Agriculture and Technology, P O Box 62000-00200 \\ Nairobi - KENYA
}

\begin{abstract}
The various benefits of e-loan application services that are implemented by institutions of high learning are linked to its adoption and usage. However, in countries that are in economically transiting state, the adoption rate of these services remains low. This therefore means that its benefits are yet to be fully realized. One of the main reasons for the slow adoption is that many governments have focused majorly on the technical supply-side factors, laying little prominence on the students' perspective of e-loan embracing. Hence little is known about the students' reactions to this new technology dispensation. The effect of this disparity is between what is provided and what is utilized. This paper utilized the Technology Acceptance Model and the signaling theory as pivotal frameworks in an effort to positively understand the factors that would influence the students' desire in using the loaning institutions websites for loan applications. We present the result of a study that was aimed at developing a model for e-loan service acceptance. This is an endeavor to bridge the gap that exists between the technical part of e-loan implementation and the students' perspective of using the offered services. We used the obtained necessities for the model from the investigations that we carried out to modify the Technology Acceptance Model. This new model places weight on student-based considerations for e-loaning. Our results give an insight for loaning institutions on the effective use of e-loaning services as a means of attracting more students to use this service.
\end{abstract}

Keywords: E-loaning, Technology Acceptance Model, Perceived usefulness, Perceived ease of use.

\section{Introduction}

The internet has affected virtually every sector, every function, every job and everybody. As such, we have witnessed a transition from the conventional methods of doing things such as sending letters to apply for jobs or making long loan applications. With services such as M-Shwari, one needs only press a few buttons on his mobile phone and various transactions such as withdraws, cash deposits, bank account balance and cash transfers are effected. The financial sector in Kenya seems to be the most affected one by the internet technologies. The market players in this sector have developed applications such as M-Pesa that makes business transactions faster and secure. The human resource departments have also moved from the traditional paperwork process of recruiting employees. Job seekers now prefer utilizing the web to search and apply for jobs [1]. In Kenya, these websites include Brighter Monday, Kenyan Jobs Blogspot and HotJobsKenya. Many people regard online recruitment as an important means of immediately getting a large amount of information about organizations and job-related issues [2].

The education sector has also been affected greatly by the advent of the internet and mobile telephony. Many universities now have distance-learning modules and virtual universities. The examinations systems of majority of them are web based, allowing students to access their results from any part of the globe. The government of Kenya offers students in institutions of higher learning some loans to cater for their fee and other requirements. In the recent past, the process of applying for these loans included filling a long form which then went through lengthy processes of appending signatures before ones loan can be approved. Today, the situation has changed for the better as everything seems to have moved online. To apply for a loan, one has to follow these steps: Log onto http://www.helb.co.ke/registration/index.jsp; Click create account to create an account profile with HELB; While still logged in, go to the home page and click 'fill the application form correctly'; Fill in the form carefully and make sure you save each and every step; Go back to the home page and click 'view application history' to confirm you have filled everything correctly; Go back home and click the 'print form' icon to get your hard copy documents [3].

Current trends point to the growing significance of institutional e-services. Organizational web sites are therefore seen as key components of strategic student base because they are the ones trough which many students interact with when doing their online applications. However, very little seems to be known on how web sites affect applicant attraction [4]. This paper tries to employ Technology Acceptance Model to understand factors determining students' behavioral intentions in using e-loaning websites 
Technology Acceptance Model (TAM)

\section{Related Work}

This is an information systems theory that models how users come to accept and utilize technology. The main purpose of TAM was to provide an explanation of the determinants of computer acceptance. It posits that users' adoption of any new information system is determined by the users' intention to use that system. This is in turn influenced by the users' beliefs about the system. TAMs main dependent constructs are the Behavioral Intention to Use and System Usage. Its major independent construct are the Perceived Usefulness (PU) and Perceived Ease of Use (PEOU). Fig. 1 below shows the TAM model [5].

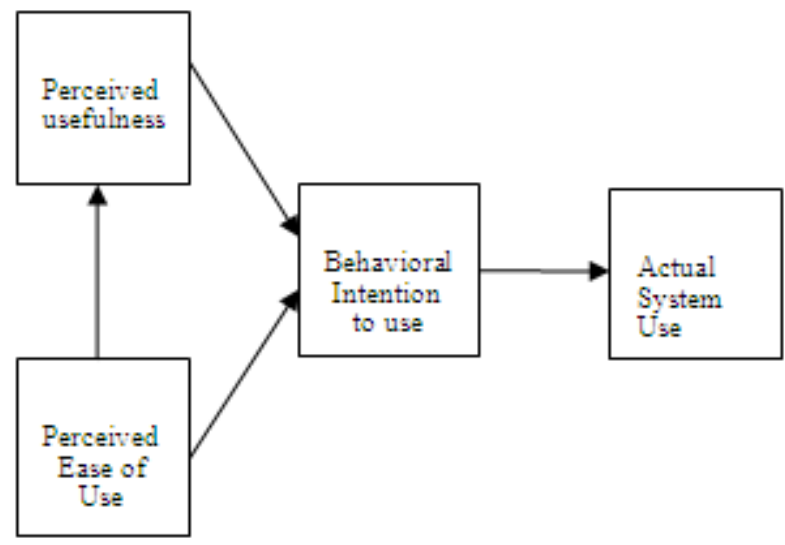

Figure 1: The Technology Acceptance Model

Perceived Usefulness is the extent to which a user believes that utilizing a given system would boost his job performance. Perceived Ease Of Use is the level to which a user believes that utilizing a particular system would be free of effort . The Behavioral Intention to Use is jointly determined by attitude and perceived usefulness. Attitude is influenced by perceived usefulness (PU) and perceived ease of use (PEOU) [5].

\section{Signaling Theory}

This theory has been used previously to investigate the potential effects of visual features of websites on users' intentions [6]. It proposes that human beings have aptitude to construe certain signs and postings from objects or expressions [7]. With regard to e-loan applicants, the signal theory may be used to determine how applicants form their impressions of the loaning institution. This is simply based on the parody of that the institution and its employees could deliver. This normally happens because applicants recognize anything or anybody related to the organization as signals of how it would feel when actually working in the institution. The signaling process specifically happens when the students have to make decisions about the loaning institution based on small amount of information. The visual characteristics of the loaning institution such as HELB's website can be the signals of the organization's principles and the reflections of the prospects of obtaining a loan.

Based on the empirical studies of the Technology Acceptance Model and its validated causal relationships among its major constructs, this paper attempted to use the structural equation modeling (SEM) to test both perceived ease of use and perceived usefulness as independent variables and behavioral intentions to apply for HELB loans online as dependent variable. To expand our model to the e-loan perspective, 2 supplementary items were introduced as external variables. These two were HELB Website Impressions (HWI) and Impression Of Loaning Institution (IOLI). This information was then used to come up with the relationships model depicted in Figure 2 below. 


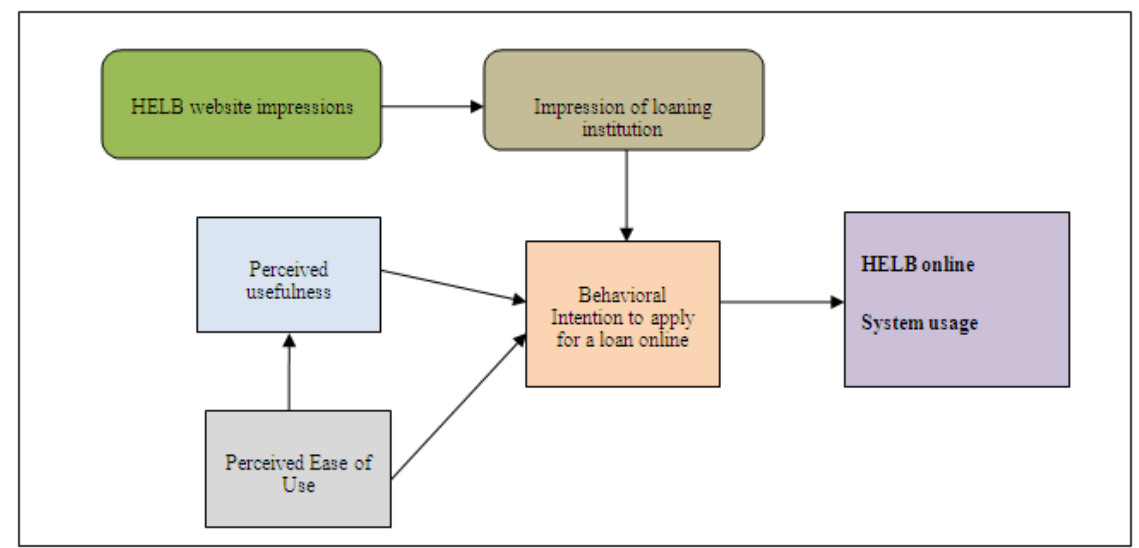

Figure 2: Research Framework

\section{Methodology}

A descriptive field study surveys using questionnaires was undertaken to establish the requirements for the model using students that get loans from HELB.

\section{Variables Measure, Sampling Population And Sample Size}

The target population of this study was HELB loan applicants of Kisii University. The data were collected in a 1-month period in 2013, during which 528 applicants logged on to HELB website. After the applications, the students were requested to fill up the survey questionnaire. The questionnaire consisted of 28 Like-type objects ( $1=$ totally disagree, $5=$ totally agree). The Perceived Ease of Use was measured with 5 objects, Cronbach Alpha of 0.91. The Perceived Usefulness was examined using the same 7 objects used by Palmer (2002), Cronbach Alpha of 0.89. The impression of the loaning institution was measured by 6 objects, Cronbach Alpha of 0.79 drawn from [8]. The website Impression was assessed by 6 objects, Cronbach Alpha of 0.86 obtained from [6]. To measure Behavioral Intention 2 items utilized by [9] were included. On top of these 2 items, an additional two measures were used. These were: (a) "If I was given an opportunity. I would apply for a loan via HELB website"; and (b) "I would come back to HELB website for loan application next semester". The last two variables were used to stress on the change of behavior due to the chance obtained.

\section{Sampling Method, Coding And Analysis}

Four hundred and fifty five questionnaires were collected. Out o these, 21 of them were incomplete, hence only 434 were used for analysis. Probability sampling method was used where every student in the entire population had a chance of being selected in the sample using simple random sampling. This method gave equal chances to all respondents identified in the study. The data obtained was grouped, quantified, coded and arranged in themes with respect to the study objectives. Afterwards, this data was tested for reliability and validity.

\section{Validity And Reliability Testing}

Validity is the degree to which given data is grounded in terms of logic or truth. Reliability on the other hand is the degree to which a given data is worthy of trust. According to [10], if the results of a study can be reproduced under similar methodology, then the instrument is regarded as being reliable. The various constructs in this study were investigated for reliability using the Cronbach's Alpha $(\alpha)$. The results are as shown in Table 1 below.

Table 1: Reliability Measures

\begin{tabular}{|l|c|}
\hline \multicolumn{1}{|c|}{ Construct } & $\boldsymbol{\alpha}$ \\
\hline E-loan adoption merits & 0.768 \\
\hline Utilization of e-loan services by students & 0.867 \\
\hline Rationale for not using e-loaning facilities & 0.798 \\
\hline Confidence & 0.845 \\
\hline Feelings towards use of e-loan services & 0.745 \\
\hline Issues hampering use of e-loan services & 0.806 \\
\hline
\end{tabular}

The acceptable level is at 0.70 [9]. From the table above, we observe that the least value of $\alpha$ is 0.745 while that largest value is 0.867 . Since these values lie well above the acceptable level, the questionnaire can hence be relied upon. 


\section{Results And Discussions}

We used the SPSS software to carry out the analysis of the items and constructs that were identified from the field research. The results we obtained are as shown in Table 2 below. The square root of average variance extracted between the constructs and their measures are shown in square brackets. We carried out a confirmatory analysis using SPSS 20 to examine the reliability, validity and general fit of the measurement model. The results of convergent validity and composite reliability of the various constructs are shown in Table 3. Convergent validity was examined based on investigative factor loadings of each objects. The composite reliabilities and variances were extracted from the latent constructs.

Table 2: Correlation Matrix Of Constructs

\begin{tabular}{|c|c|c|c|c|c|c|c|}
\hline Variable & Average & Stdev & HWI & IOLI & PEU & $\mathbf{P U}$ & BI \\
\hline Perceived ease of use (PEU) & 3.61 & 1.12 & 0.42 & 0.05 & {$[0.78]$} & & \\
\hline Behavioral Intention (BI) & 2.89 & 0.88 & 0.39 & 0.46 & 0.34 & 0.42 & {$[0.76]$} \\
\hline
\end{tabular}

The established the recommended loading factor to be 0.5 [11]. From Table 3, we observed that all the loading factors surpass this value. The composite reliabilities indicate the internal consistency of the measurement model [12]. This value is at minimum of 0.7. Comparing this value with the figures obtained in the table above (minimum of 0.816 and maximum of 0.923 ). The average variance indicates convergent validity [13]. Extracted values were well above the minimum figure of 0.5[14] recommended that we compare our model with other competing models that act as alternative explanations to the projected model. According to Byrne, 2009, this comparison permits us to conclude that the final model is acceptable. This is because no other similar formulated model could achieve the same level of fit.

From Table 3, since the correlation of each construct is lower than the square root of the average variance extracted, then the model showed adequate reliability. In order that we come up with a final attuned model, we calculate the path estimates $(\rho)$ between the various constructs. Since our model showed adequate reliability as well as both convergent and discriminant validity. All the indices indicated an accepted level of fit for the measurement model. These figures are $\mathrm{X}_{2} /$ d.f. of 2.91 ; root mean square error of approximation of 0.071 ; normalized fit index of 0.921; and comparative fit index of 0.867 . In each substitute model, one parameter changed at a time and the fit indices were compared with those of the proposed theoretical [15]. The obtained results indicated that the final attuned model fitted the data to a satisfactory level of $\mathrm{X}_{2} / \mathrm{d}$.f. of 2.84 ; root mean square error of approximation of 0.067 ; goodness of fit of 0.815 ; normalized fit index of 0.918; Tucker-Lewis index of 0.914; and comparative fit index of 0.931. To help with the calculations of $\rho$, we used Figure 3 that is shown below. 
Examining the Technology Acceptance Model for E-Loan Application Services among .....

Table 3: Confirmatory Factor Analysis For The Measurement Model

\begin{tabular}{|c|c|c|c|c|}
\hline \multirow[t]{2}{*}{ Construct } & \multirow[t]{2}{*}{ Item } & \multicolumn{3}{|c|}{ Convergent validity } \\
\hline & & Factor loading & Composite Reliability & Variance extracted \\
\hline \multirow{6}{*}{$\begin{array}{l}\text { HELB website } \\
\text { impressions(HWI) }\end{array}$} & HWI1 & 0.82 & 0.829 & 0.622 \\
\hline & HWI2 & 0.78 & & \\
\hline & HWI3 & 0.77 & & \\
\hline & HWI4 & 0.71 & & \\
\hline & HWI5 & 0.76 & & \\
\hline & HWI6 & 0.81 & & \\
\hline \multirow{6}{*}{$\begin{array}{l}\text { Impression of loaning } \\
\text { institution (IOLI) }\end{array}$} & IOLI1 & & & \\
\hline & IOLI2 & 0.72 & 0.847 & 0.564 \\
\hline & IOLI3 & 0.79 & & \\
\hline & IOLI4 & 0.80 & & \\
\hline & IOLI5 & 0.74 & & \\
\hline & IOLI6 & 0.69 & & \\
\hline \multirow[t]{5}{*}{ Perceived ease of use (PEU) } & PEU1 & 0.76 & 0.816 & 0.613 \\
\hline & PEU2 & 0.79 & & \\
\hline & PEU3 & 0.73 & & \\
\hline & PEU4 & 0.75 & & \\
\hline & PEU5 & 0.87 & & \\
\hline \multirow[t]{7}{*}{ Perceived Usefulness (PU) } & PU1 & 0.77 & 0.923 & 0.663 \\
\hline & PU2 & 0.75 & & \\
\hline & PU3 & 0.84 & & \\
\hline & PU4 & 0.76 & & \\
\hline & PU5 & 0.83 & & \\
\hline & PU6 & 0.80 & & \\
\hline & PU7 & 0.88 & & \\
\hline \multirow[t]{4}{*}{ Behavioral Intention (BI) } & BI1 & 0.86 & 0.854 & 0.642 \\
\hline & $\mathrm{BI} 2$ & 0.87 & & \\
\hline & $\mathrm{BI} 3$ & 0.69 & & \\
\hline & BI4 & 0.74 & & \\
\hline
\end{tabular}

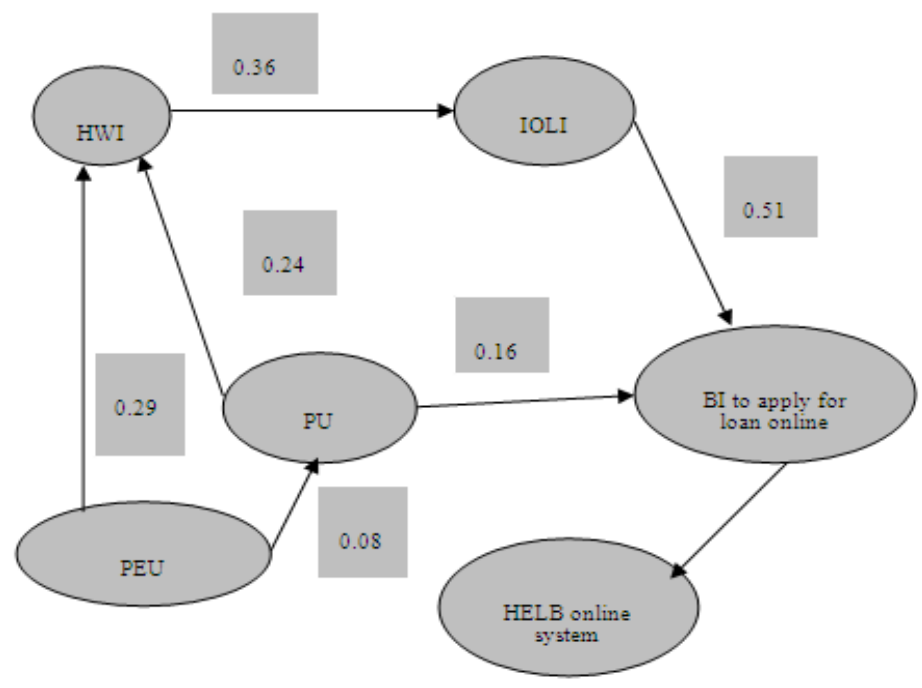

Figure 3: Final Attuned Model

\section{Conclusion}

In this paper, we developed a framework based on the technology acceptance model and the signaling theory to explain on the various factors that influence the students' intention to use HELB online system to apply for university loans. We noted that there was a positive relationship between PEU and HWI with a path coefficient of 0.29. There is also a positive relationship between PU and HWI with a path coefficient of 0.24 . Similarly, there was a positive relationship between IOLI and HWI (path coefficient of 0.36) and a positive relationship between IOLI and BI (path coefficient of 0.51). Due to the positive correlation between PU and BI, in the online loan applications, usefulness is vital as it measures the extent to which the design of interactive tools in HELB website affect the student access to treasured information. The positive association of both PEU and PU with the students' impression of the HELB website suggests that navigability and content information 
are among the factors influencing students' HWI. The study confirms the mediating function of impressions of the loaning institution on the relationship between HWI and students' intentions to apply for the loan online. For example, a complex website for HELB would make students think that getting a loan from the institution is going to be a complex process just like its website! Therefore, besides ease of use and usefulness as two main components of the technology acceptance model, the HELB website impression can in reality affect the students' intentions to apply for loans. This paper's findings are important as it does not only broaden the technology acceptance model to the e-loan services but also contributes to the enhanced understanding of how websites features such as easy of navigation manipulate students' application decisions in Kenya. The loaning institutions and the information system designers can utilize the results of this paper as a basis of improving the e-loaning process.

\section{References}

[1]. D. Hooper, "Getting better all the time", HR Monthly, May 2007.

[2]. H. Sylva, \& . Mol, "E-recruitment: A study into applicant perceptions of an online application system", International Journal of Selection and Assessment, 17,2009, 311-323.

[3]. Musolix, "How to Apply for HELB; Easy Guide", 2013.

[4]. R. Cober, D. Brown, L. Keeping, \& P. Levy, “ Recruitment on the net: How do organizational website characteristics influence applicant attraction", Journal of Management , 30 2004, 623-646.

[5]. M. Gilbert \& A. Elizabeth, "Adoption of E-tax services in Uganda: The Perspective of the Technology Acceptance Model", Strengthening the Role of ICT in Development, Volume VIII , 2012.

[6]. L. Thompson, P. Braddy, \&K. Wuensch, "E-recruitment and the benefits of organizational web appeal", Computer in Human Behavior, 24,2008, 2384-2398.

[7]. M. Luxen \& P. Buunk, “Human intelligence, fluctuating asymmetry and the peacock's tail: General intelligence”, 2006.

[8]. S. Highhouse, F. Lievens, E. Sinar, \& G. Lautenschlager, "Measuring attraction to organizations", Educational and Psychological Measurement, 63,2008, 986-1001.

[9]. Cronbach, L. (1970), “Essentials of Psychology Testing”, New York, USA, Harper and Row.

[10]. P. Jopper, "Web site usability, design, and performance metrics", Information System Research, 13, $2012,151-167$.

[11]. D. Straub, "Validating instruments in MIS research", MIS Quarterly, 13, 1989, 147-169.

[12]. D. Gefen, D. Straub, D., \& M. Boudreau, "Structural equation modeling and regression: Guidelines for research practice", Communications of the Association of Information Systems, 4, 2000, 1-79.

[13]. R. Bagozzi, \& Y. Yi, "On the evaluation of structural equation models", Journal of the Academy of Marketing Science, 16,1988, 74-94.

[14]. J. Hair, H. Anderson, E. Tatham, \& W. Black, “ Multivariate data analysis”, Upper Saddle River, NJ: Prentice-Hall, 1998.

[15]. B. Byrne, "Structural equation modeling with AMOS: Basic concepts, applications, and programming", 2nd ed. New York: Taylor \& Francis Group, 2009. 